\title{
Enhanced photovoltaic performance of silver@titania plasmonic photoanode in dye- sensitized solar cells
}

\begin{abstract}
In the present investigation, silver@titania (Ag@TiO2) plasmonic nanocomposite materials with different Ag content were prepared using a simple one-step chemical reduction method and used as a photoanode in high-performance dye-sensitized solar cells. Transmission electron microscopic images revealed the uniform distribution of ultra-small Ag nanoparticles with a particle size range of $2-4 \mathrm{~nm}$ on the $\mathrm{TiO} 2$ surface. The incorporation of $\mathrm{Ag}$ on the $\mathrm{TiO} 2$ surface significantly influenced the optical properties in the region of $400-500 \mathrm{~nm}$ because of the surface plasmon resonance effect. The dye-sensitized solar cells (DSSCs) assembled with the Ag@TiO2-modified photoanode demonstrated an enhanced solar-toelectrical energy conversion efficiency (4.86\%) compared to that of bare $\mathrm{TiO} 2(2.57 \%)$, due to the plasmonic effect of $\mathrm{Ag}$. In addition, the $\mathrm{Ag}$ nanoparticles acted as an electron sink, which retarded the charge recombination. The influence of the Ag content on the overall efficiency was also investigated, and the optimum Ag content with $\mathrm{TiO} 2$ was found to be 2.5 wt $\%$. The enhanced solar energy conversion efficiency of the Ag@TiO2 nanocomposite makes it a promising alternative to conventional photoanode-based DSSCs.
\end{abstract}

Keyword: Conversion efficiency; Dye-sensitized solar cells; Nanocomposites; Nanoparticles; Plasmons; Solar cells; Solar energy; Titanium dioxide 